\title{
A METHOD OF HIP ARTHROPLASTY
}

\author{
F. P. Fitzgerald, London, ENGLANd
}

The method of mould arthroplasty described by Smith-Petersen in 1939 has been accepted throughout the world. In 1943 Moore and Bohlman published a report of a case demonstrating a metal hip joint, and in 1948 Martin showed a prosthesis consisting of a solid steel head with a screw shank. One year later Robert and Jean Judet demonstrated the use of an acrylic head for arthroplasty of the hip. In 1951 Peterson published a description of another type of solid steel head and shank, the Jaenichen-Collison prosthesis. All these methods have influenced the design of the prosthesis described below.

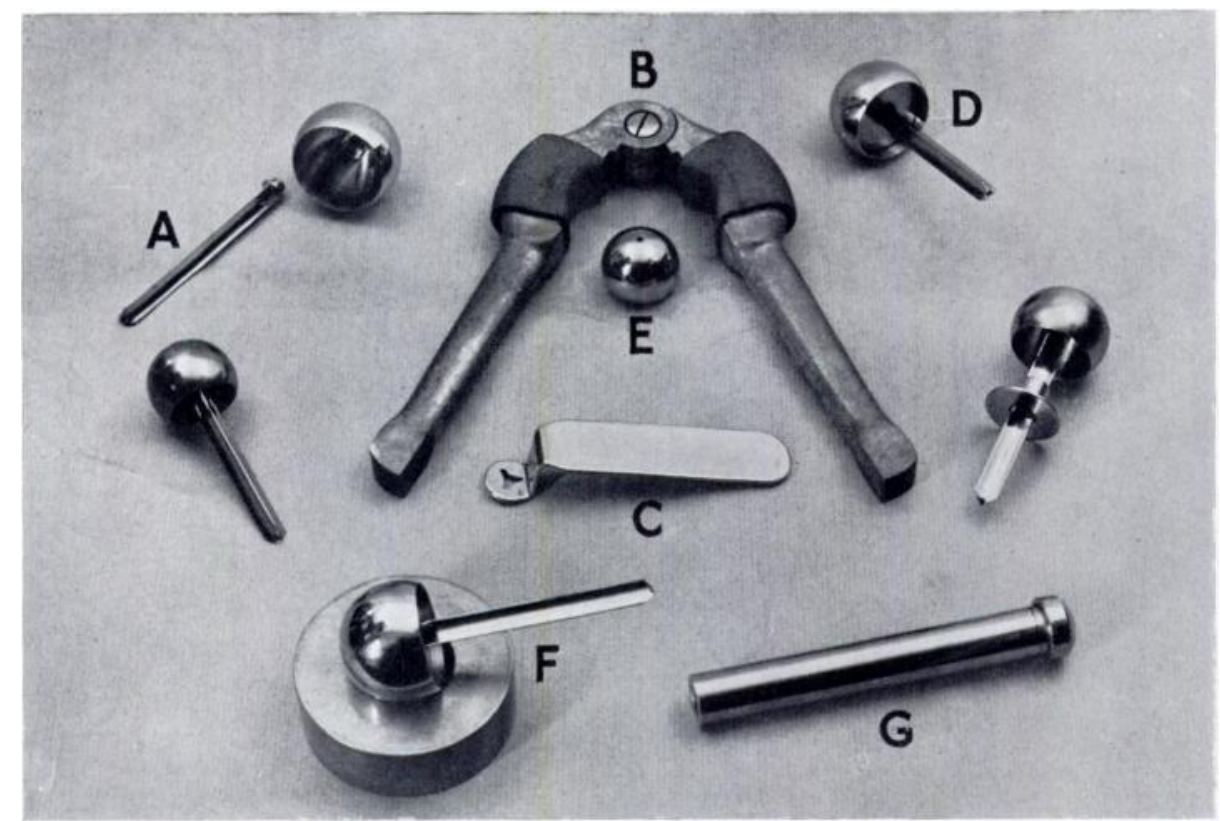

Fig. 1

A shows the cap and nail separately and (below) connected. Note the raised edge on the boss for riveting. $B$ is the special "grip" for holding the head. C is the spanner which fits the trifin nail. D shows the special washer and distance-piece being fitted. E shows the perforation in the cap. 1:-Prosthesis and stamping plate. (;-riveting punch which is threaded over the nail and rivets the nail in place.

\section{THE PROSTHESIS}

The prosthesis consists of a hollow steel cap, resembling Smith-Petersen's cup or mould, to the inside of which is fixed a cannulated trifin nail (Fig. 1). The caps are made in four sizes. The nails are smaller than the standard Smith-Petersen nails, the diameter being ten millimetres instead of thirteen. The sharp ends of the nails are tapered and have saw-tooth edges, which prevent splitting of the neck of the femur. The other end of the nail is threaded so that it can be screwed and countersunk into a boss on the inside of the cap, using the special holders and spanner (Fig. 1). The prosthesis is light and strong. The nails are made in different lengths, like the standard Smith-Petersen nails. If an artificial head is desired instead of a cap, a special washer is threaded over the nail and the prosthesis thus changed into a hollow steel head which resembles the Judet acrylic head. 
The prostheses of Bohlman, Jaenichen-Collison, Martin and Judet all have solid heads and stems. By their size and shape the stems tend to disturb the nutrition of the neck of the femur. Because of this, it is possible that in the course of years the bone may become damaged or the prosthesis may work loose. These types of prosthesis have an insecure hold on the remnant of the neck of the femur, and it is sometimes difficult to gauge the exact position of the shank in the neck.

The appliance described in this article has several advantages. The trifin shank does little damage to the bone, and since it is cannulated it can be threaded over a guide wire and placed accurately in the centre of the femoral neck. The exact length of stem necessary can be found from the guide wire and a suitable nail chosen. In osteoarthritic hips the head of the bone is not excised but trimmed accurately with a special cutter to take the hollow cap (Fig. 2). This ensures a strong buttress of bone for the appliance. It has already been mentioned that by the addition of a special washer the cap can be used as a hollow steel

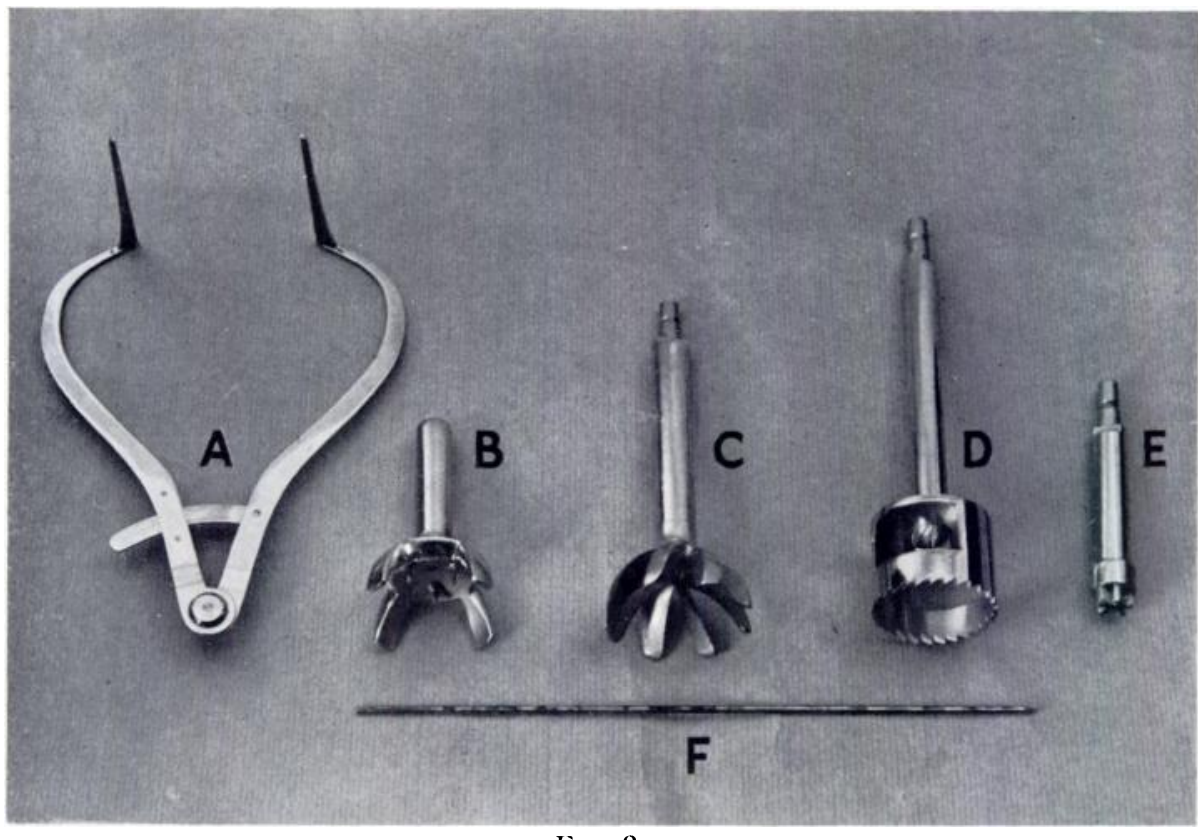

Fig. 2

1-Calipers for measuring the head of the femur. B-Guide through which guide wire (I) is passed into the dislocated head. C-The head reamer. D-A head cutter. There are four sizes to correspond to the caps. E-countersink borer. F-Special guide wire. It is larger than the standard Watson-Jones type.

head (Fig. 1) when it is not possible to retain the femoral head, as in fractures of the neck. (It is possible to fit a trifin nail to a cannulated acrylic head, but this does not seem to have any advantage over the steel one.) The acetabulum is not remodelled unless it is unaroidable, as in bony ankylosis of the hip joint.

\section{TECHNIQUE OF OPERATION}

Smith-Petersen's approach is used. Special instruments used are shown in Figure 2 . The head of the femur is dislocated in the usual way, and its diameter measured with a caliper. A guide is fitted to the femoral head, and a guide wire is passed downwards through the head and neck of the femur. Radiographs confirm the position of the guide. A head reamer is then fitted over the guide wire and the contour of the head shaped to fit the inside of the cap. A head cutter is then threaded over the guide wire and the circumference 
of the head is reduced so that the diameter corresponds accurately to that of the cap to be used. A counter borer is then passed over the guide wire, and a small area cut out to take the buttress on the inside of the femoral cap. A special starter is passed over the guide wire and tapped gently down through the femoral neck. A nail of suitable length is screwed firmly into the femoral cap, and the edge of the boss is tapped over by a riveting punch to prevent the nail becoming loose. The combined nail and head are threaded over the guide wire, and tapped into place with a cannulated punch. The new femoral head is

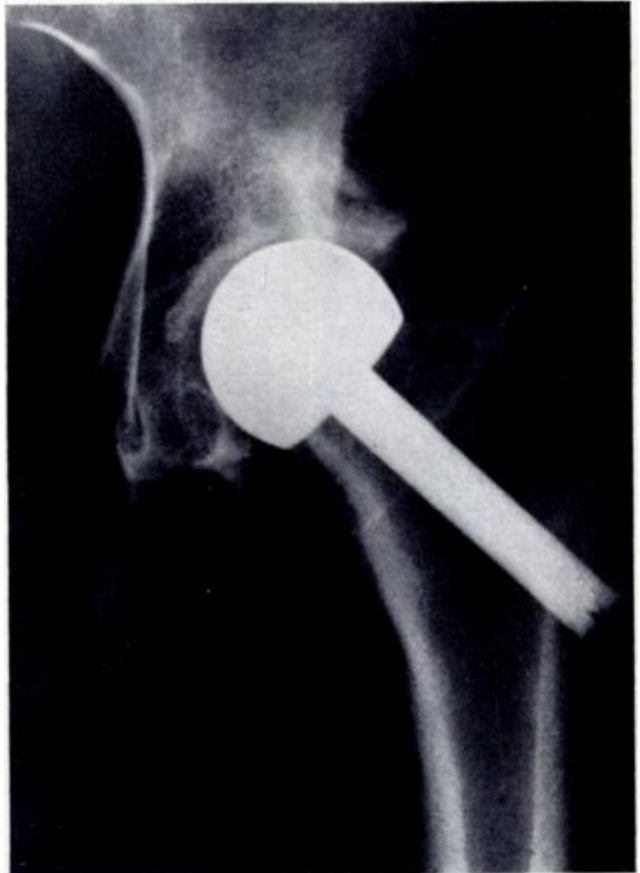

FIG. 3

Radiograph showing the prosthesis in the acetabulum, which has not been deepened or reamed reduced into the acetabulum (Fig. 3) and the incision is closed.

Post-operative treatment-The first few cases were treated vigorously. Active movements were begun on the third day and every attempt was made to increase the range of movement as rapidly as possible. Since then a more moderate routine has been instituted. Traction is maintained on the limb, and gentle movements only are allowed after three weeks. "Skating" and assisted active exercises are increased until the sixth week, when the patients are allowed to get up and encouraged to walk in a walking chair. The results of the two methods of post-operative treatment appear to be identical. Since the less forcible procedure is more comfortable for the patient, it has been adopted as the routine treatment.

\section{COMMENT}

This operation for arthroplasty of the hip has been used in seventeen cases, the youngest patient being forty-four years of age and the oldest seventy-one. Before operation, all the routine methods of physical treatment were tried and surgery was considered only when there was no improvement. All the patients have been operated upon within the past year, and it is therefore not possible to reach a final judgment on the results. It can be said, however, that most patients are free from pain and have an excellent range of movement.

My thanks are due to Miss Hathway, the superintendent radiographer at the Roval Northern Hospital, who has given much time and thought to the radiographic technique. Messrs Down Brothers made the instruments, and a special word of thanks is due to Mr Maurice Down for his courtesy and patience.

\section{REFERENCES}

J'DET, R., and J'DET, J. (1949): Essais de reconstruction prothétique de la hanche aprís résection de la tête fémorale. Journal de Chirurgie, 65, 17.

Martix, J. D.: Prosthesis shown at British Orthopaedic Association meeting. Relfast, 1948.

Moore, A. T., and Bohlmax, H. R. (1943) : Metal Hip Joint. A (ase Report. Journal of Bone and Joint Surgery 25, 688 .

Peterson, L. T. (1951): The Use of a Metallic Femoral Head. Journal of Bone and Joint Surgery, 33-A, 65. Smith-PEtersen, M. N. (1939) Arthoplasty of the Hip a New Method. Journal of Bone and Joint Surgery, 21, 269. 